\title{
Brightness variability in the white badge of the eagle owl Bubo bubo
}

\author{
Vincenzo Penteriani, Carlos Alonso-Alvarez, María del Mar Delgado, Fabrizio Sergio and Miguel Ferrer
}

\begin{abstract}
The application of modern spectrometry to the study of avian colour variability has revealed ignored patterns of colour variation such as male-biased sexual dichromatism and seasonal variability in the plumage. However, the variation in the achromatic property of such traits, that is in the total light reflectance of the spectrum (i.e., brightness), has commonly been overlooked. The evolution of signals based on brightness should be favoured in those species that are active when light is scarce, i.e. at dawn and dusk. The eagle owl Bubo bubo is monogamous and apparently monomorphic in plumage-coloration. In this species, sexual and territorial call behaviour is mainly performed at dawn and dusk, during which a white patch on the throat is repeatedly exposed at each call. We measured the total light reflectance of the feathers of this badge in 39 eagle owl specimens from museum collections. We found seasonal variability and sexual dichromatism in the brightness of the plumage badge. The total reflectance of this trait peaked during the territorial-mating period. Moreover, females showed higher values of brightness than males, in agreement with the reversed body size dimorphism present in this and many other raptor species. Finally, female but not male body size was positively correlated with white badge reflectance.
\end{abstract}

V. Penteriani (correspondence), M.M. Delgado, F. Sergio and M. Ferrer, Department of Conservation Biology, Estación Biológica de Doñana, C.S.I.C., Avda. de María Luisa s/ n., Pabellón del Perú, Apdo 1056, 41013 Seville, Spain. E-mail: penteriani@ebd.csic.es. C. Alonso-Alvarez, Departamento de Ecoloxía e Bioloxía Animal. Universidade de Vigo. EUET Forestal. 36005. Pontevedra. Spain.

Animals show an extreme diversity of strategies to signal their presence as territory owners, or as potential mates. Variability in coloration is one of them. Achromatic plumage patches, i.e. those showing pigment-free white feathers and/or variability in the amount of melanin, have attracted interest of evolutionary biologists due to its role in signalling individual status, or predicting mating preferences (e.g., Møller 1987, Griffiths et al. 1999). However, although its presence is widespread among avian species, achromatic plumage is commonly analysed in terms of individual variability in size or design (e.g., Pärt and Qvanströ m 1997, Griffiths et al. 1999, Sæther et al. 2000, Thusius et al. 2001). Only a recent avian study described status-related variability and sexual dichromatism in the amount of total intensity of the light spectrum (320-700 nm, also known as "total reflectance"” or "brightness"; Endler 1990) of an achromatic trait, the white and black plumage of the black-capped chickadee Poecile atricapilla (Mennill et al. 2003).

Sexual dichromatism is expected to evolve under the pressure of sexual selection (Andersson 1994, Owens and Hartley 1998). A growing amount of scientific literature is currently showing that in many species the evolution of secondary sexual traits, such as plumage, may also be due to mutual inter- and intrasexual selection taking place in both sexes (i.e., mate choice and male-male or female-female competition, respectively; e.g., Berglund et al. 1996, Jones and Hunter 1999, Amundsen 2000, Daunt et al. 2003). This would be particularly expected in sexually monomorphic species with monogamous breeding systems and similar roles in reproduction (Darwin 1871, Jones and Hunter 1993). 
The eagle owl Bubo bubo is an apparently sexually plumage-monomorphic and socially monogamous species, presenting a white badge on the throat that is only visible during call displays (Penteriani 1996). Eagle owl body feathers do not moult every year, showing an unequal periodicity (Cramp 1985, Martínez et al. 2002). The white patch on the throat is repeatedly exposed (inflated and deflated) at each call and its visibility is increased by the typical posture that eagle owls assume when calling. Both males and females display this apparently identical trait (Penteriani 1996). Call displays are mainly performed by males, but females may also show high call rates during the territorial-mating period, especially when a male is absent from the nest surroundings (Penteriani 2002, 2003). Moreover, females sometimes lead the vocal duets and the males only reply to the females' calls. Such vocal behaviour is associated with intra- and intersexual territorial disputes, as well as courtship behaviour (Penteriani 2002), both taking place during the whole year, with a peak in the period between juvenile dispersion and egg laying (Penteriani 2002).

Eagle owl mainly shows diurnal and crepuscular (i.e., sunset and sunrise) patterns of activity (Cramp 1985, Penteriani 2000, 2002). Any visual signal used around dawn and dusk should maximize the use of the scarce light available. Therefore, the eagle owl's white badge could be a good candidate to present sexual dichromatism and/or other overlooked patterns in the total amount of reflected light.

Here, we analysed the size and the variability in brightness of the eagle owl's white badge. We explored potential patterns of variation related to sexes and seasons, for a better understanding of the functionality of this trait. We predicted higher values of total reflectance during the territoriality-mating period, following the classical Darwin (1871)'s suggestion about the pattern of seasonal variability of sexually dimorphic traits subject to sexual selection. In contrast, in the case of a possible sexual dichromatism, a priori predictions on the sign of the difference were not formulated because of our lack of knowledge about how selective pressures (mate choice and intrasexual competition) could act in this species.

\section{Methods \\ Specimen collection and morphological measurements}

We took feather samples of the white throat of specimens belonging to the two largest bird collections of Spain, those of the Estación Biológica de Doñ ana in Seville and of the National Museum of Natural Science in Madrid (both from Consejo Superior de Investigaciones Científicas-CSIC). The specimens were dated between 1913 and 1999 (males: 1913-1999; females 1916-1999). They were not exposed specimens, preserved in opaque bags, thus preventing the negative effect of light. Any specimen showing a poor conservation state were directly discarded for the analysis (i.e., poor feather integrity or visible presence of chemical products on the surface; see Eaton and Lanyon 2003). Moreover, we only studied those individuals for which sex was determined by gonad inspection. Thus, 39 specimens (20 males and 19 females) were available for analysis.

The white badge of the eagle owl can be divided in two parts: a small one, just below the bill, and a large one on the throat. In order to know if differences in the size of the with badges were present, digital pictures (Panasonic NV-MX7EG, Osaka, Japan) were taken for both small and large white patches, as well as for the total face surface, all taken from the same perspective and distance. The photos were obtained after flattening the badge with a glass to measure its maximum extent. Pictures were analysed by the ImageJ $1.28 \mathrm{u}$, a Java image-processing program (http://rsb.info.nih.gov/ij/), calculating the area of both parts of the badge and for the whole of the face area. Afterwards, a sample of feathers from the large white patch was taken for spectrometric measurements.

In order to obtain an individual estimate of body size, forearm length was measured with a ringing rule (91 mm). Although sexual size dimorphism is subtle, this measurement is a significant predictor of sex in this species (Delgado and Penteriani 2004) and was the only measure that could be collected from a large number of specimens $(n=29)$.

\section{Spectrometric measurements}

Coloration of eagle owl throat feathers was quantified using a spectrometer (Ocean Optics Europe). Measurements were made in the range $320-700 \mathrm{~nm}$ (Fig. 1) under controlled laboratory conditions.

The feathers were subjected to a light source (DH2000, Top Sensor System) with a spectral range from 280 to $800 \mathrm{~nm}$. They were placed under a metal

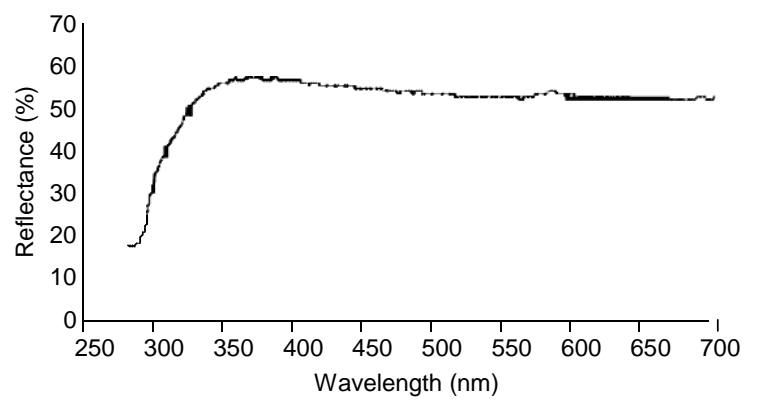

Fig. 1. Example of reflectance spectra of eagle owl white badge feathers. 
chamber provided with a magnifying lens pointing at the part of the feather to be illuminated by the light source, which excluded (by a black cover) ambient light during measurement. Two quartz optic fibres (Ocean Optics) were fixed at 908 and 458 to the surface of the sample on the metal chamber. The first fibre transferred the light (that thus reached the sample perpendicularly) from the source lamp to the feather, and the second one collected the reflected light and transferred it to the spectrometer (S2000). A DAQ Card 700 converted the data collected by the spectrometer into digital information and passed it to a computer software (Spectrawin 3.1) calculated reflectance data relative to a white reference tile (WS-2) and to the dark from 320 to $700 \mathrm{~nm}$. All samples were measured during the same session. Both white and dark references were recorded under the same metal chamber before the session of measurements started, and they were checked regularly during measurements.

Feathers from eagle owl throat are similar to down, with two distinguishable parts: a very delicate and light periphery and a more consistent central area near the rachis. We decided to separately measure reflectance in these two areas because seasonal variability in structural colours could be due to the wear of the feathers (i.e., Örnborg et al. 2002), and therefore could be only detected in the most exposed areas.

Three measurements (each being an average of 10 scans) were made on each part of the feather (three on the tip and three on the centre of the feather). Since throat feathers are very light, four superimposed feathers were measured each time. These four feathers were collected at random by an independent person unaware of each bird identity. The metal chamber was entirely moved and the four feathers randomly mixed between successive measures. The area of the visible surface of the feathers that was measured was about $1 \mathrm{~mm}$ wide. All measurements were made by the same person (C.A.-A.), and they were done blindly with respect to the identity of individuals.

The software Spectrawin gives a value for the black and white references and the sample reflectance data at each $0.4 \mathrm{~nm}$ interval (n) between 300 and $700 \mathrm{~nm}$. Percentage reflectance at each $n$ point could be calculated with a software by the formula: $R(n)=$ ([sample (n)—dark (n)]/[white (n) - dark (n)]) $>100$. Thus, four different variables were calculated. Total reflectance (also "brightness") was the sum of reflectance data in the interval $320-700 \mathrm{~nm}$. Such variable could be considered as an index of whiteness, highest values showing the purest white colour.

The UV range of reflectance $(320-400 \mathrm{~nm})$ was included in the brightness measurement. This assumes the fact that many avian species are able to see UV light (Cuthill et al. 2000). In fact, a large proportion of individuals showed badge feathers with peaks under the $400 \mathrm{~nm}$ UV threshold (31\% and 46\% for tip and feather centre, respectively; see example in Fig. 1). However, neither sex nor season showed a significant influence on hue $(\mathrm{P}>0.25)$. There is no available data about the characteristics of the eagle owl vision and the only owl species previously studied the tawny owl Strix aluco, is not able to see in this range (Bowmaker and Martin 1978). Nevertheless, we conservatively repeated the analyses excluding $320-400 \mathrm{~nm}$ range and the results were almost identical (PB0.05 for both sex and season factors and no effect of sample age; $\mathrm{P}>0.10$ ).

\section{Repeatability of the estimates of reflectance parameters}

We estimated the reliability of our data by making repeated measurements to obtain estimates of repeatability (Lessels and Boag 1987). During these measurements, the optic fibre was removed and replaced on the feather in a standardized way between each measurement as described above.

Repeatability within all measurements was always highly significant for both feather tip $(\mathrm{R}=0.64, \mathrm{~F}=$ 3.59, $\mathrm{df}=75, \mathrm{~PB} 0.001)$ and feather centre $(\mathrm{R}=0.52$, $\mathrm{F}=2.19$, $\mathrm{df}=78, \mathrm{P}=0.002$ ). Therefore, mean values from the four measurements were used for analyses. Repeatability was lower when tip and centre measurements (six in total) were included at the same test ( $\mathrm{R}$ lower than 0.25). Moreover, mean measurements from tip and centre were not correlated within individuals (always $\mathrm{P}>0.25$ ).

\section{Statistical analyses}

General Linear Models (GLM) were used to test the influence of sex and season on the white badge areas and brightness (dependent variables). In order to control for head size, total face surface was introduced as a covariate in those models analysing the variability in the surface of the white patches. In addition, the age (i.e., year when birds were collected) of the sample was included in the models testing brightness variability because the amount of total reflectance may depend on delicate microstructures that could be sensitive to long conservation periods (Mahler and Kempenaers 2002). For this reason, because the effect of sample age could mask the effect of other factors, sequential sum of squares (type I) was used. Thus, age was introduced as a first step, adding afterwards each fixed factor and their interactions. The non-significant terms $(\mathrm{P}>0.05)$ where then removed from the model to give the minimum adequate model (Crawley 1993). "Season"' was a twolevel factor divided in "territorial-mating period" (from September to February, i.e., during the peak of vocal displays in the pre-laying period), and "breeding period" (from March to August, i.e., between egg-laying and the 
beginning of juvenile dispersion). The attribution of a specimen to a season was done by the date corresponding to when the individual was collected. Both periods were estimated on the basis of the breeding behaviours and cycle of Spanish eagle owls (Ruiz-Martínez et al. 1996, Penteriani 2002, Delgado and Penteriani unpubl. data). Spearman correlation coefficients were used to relate reflectance to body size due to the low sample size and the non-normal distribution of the forearm. All tests were two tailed. All GLMs met the homocedasticity assumption (tested by means of Levene's F tests). All statistical analyses were performed with SAS software (version SAS 8.2; SAS Institute 2001).

\section{Results}

Size variability of white patches

The size of both small and large white badges did not vary with sex (small: $\mathrm{F}=2.49$, $\mathrm{df}=1.34, \mathrm{P}=0.12$; large: $\mathrm{F}=0.001$, $\mathrm{df}=1.34, \mathrm{P}=0.98$ ), or season (small: $\mathrm{F}=$ 2.28, $\mathrm{df}=1.34, \quad \mathrm{P}=0.14$; large: $\mathrm{F}=3.09$, $\mathrm{df}=1.34$, $\mathrm{P}=0.09$ ), or their interaction (small: $\mathrm{F}=0.49$, $\mathrm{df}=$ 1.34, $\mathrm{P}=0.49$; large: $\mathrm{F}=0.72$, $\mathrm{df}=1.34, \mathrm{P}=0.40$ ). The covariate-effect of total face surface was significant in the case of the small patch $(\mathrm{F}=4.38, \mathrm{df}=1.34, \mathrm{P}=$ $0.045)$, but not in the case of the large patch $(\mathrm{F}=1.74$, $\mathrm{df}=1.34, \mathrm{P}=0.20)$.

\section{Total reflectance in the white patch}

Total reflectance varied with sex and season (Table 1). In the case of the tip of the feather, we found that brightness was season-dependent, being higher in the territorial-mating period (Fig. 2A), but neither the effect of sex $(P>0.50)$ nor the sex $x$ season interaction $(P>0.60)$ were significant. The coefficients of variation were $18.3 \%$ and $27.8 \%$ for territorial and breeding periods, respectively. The age of the sample had not a significant effect $(\mathrm{F}=3.84, \mathrm{df}=1.35, \mathrm{P}=0.06)$, and therefore was removed from the model.

Table 1. General linear models showing the effect of season ( $>$ values during the territorial - mating period) and sex ( $>$ values in females) on the total reflectance of two different parts of the white badge feathers.

\begin{tabular}{lrrcc}
\hline & $\mathrm{F}$ & $\mathrm{df}$ & $\mathrm{P}$ & $\mathrm{R}^{2}$ \\
\hline $\begin{array}{l}\text { Feather tip } \\
\quad \text { Model }\end{array}$ & 4.59 & 1 & 0.039 & 0.113 \\
$\quad \begin{array}{l}\text { Error } \\
\quad \text { Season }\end{array}$ & 4.59 & 1 & 0.039 & \\
$\begin{array}{l}\text { Feather centre } \\
\quad \text { Model }\end{array}$ & 5.24 & 1 & 0.028 & 0.124 \\
$\quad$ Error & 5.24 & 1 & 0.028 & \\
$\quad$ Sex & & & & \\
\hline
\end{tabular}
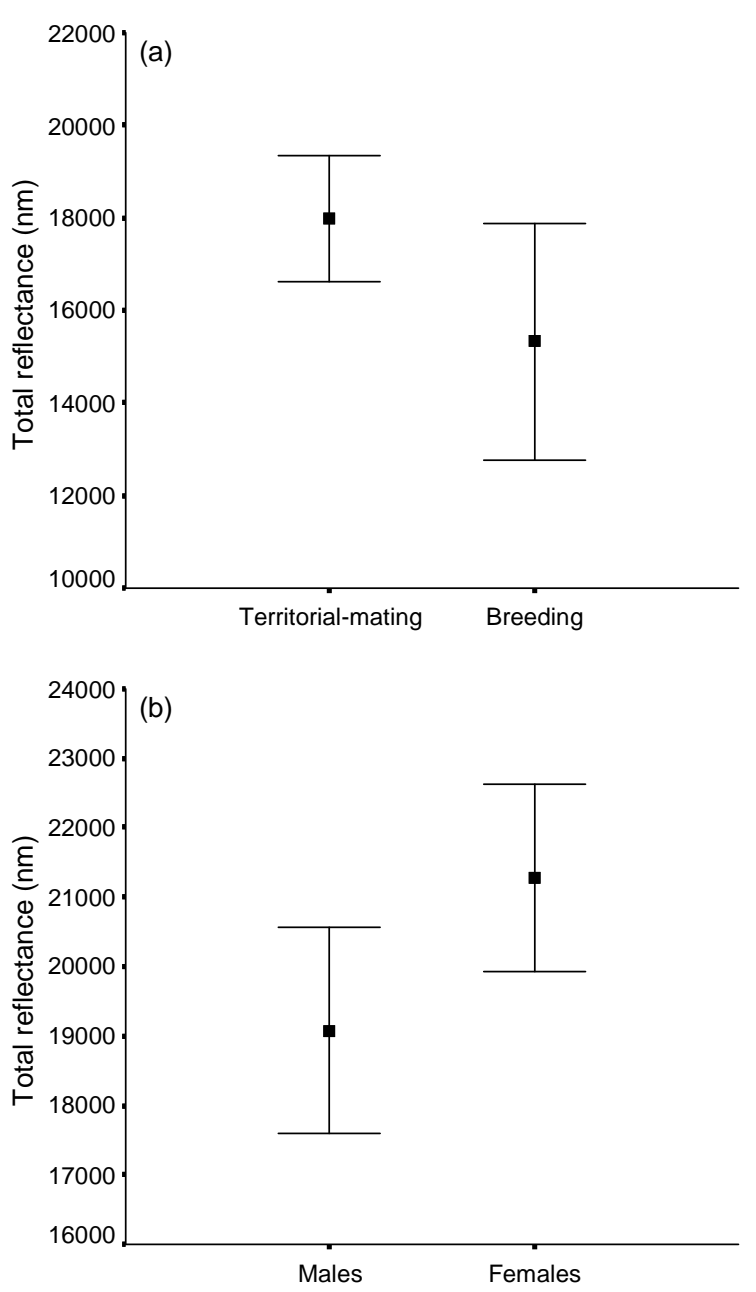

Fig. 2. Differences between seasons (feather tip, a) and sexes (feather centre, b) in the total reflectance of the white patch of the eagle owl (means $\$ 95 \%$ confidence intervals).

When considering the centre of the feathers (Table 1), total reflectance was sex-dependent, females being the sex with higher brightness (Fig. 2B). The coefficients of variation were $16.6 \%$ and $13.2 \%$ for males and females, respectively. Neither the seasonal period $(\mathrm{P}>0.30)$ nor the sex $x$ season interaction $(P>0.25)$ seemed to affect total reflectance. Again, the age of the sample did not influence the result $(\mathrm{F}=0.63, \mathrm{df}=1.36, \mathrm{P}=0.43)$.

\section{Body size and sex differences}

Since females showed higher levels of reflectance, and assuming the possibility that the white patch could signal individual quality (i.e., larger females can accumulate greater fat reserves prior to incubation, with consequent advantages in the incubation and brooding periods; Massemin et al. 2000), we examined the relationship between individual variability in brightness and body 
size. We correlated the size of the forearm with the total reflectance measured in the feather centre. Whereas males did not show a significant relationship $(r=0.26$, $\mathrm{P}=0.33, \mathrm{n}=16$ ), females showed a significant positive correlation ( $\mathrm{r}=0.62, \mathrm{P}=0.023, \mathrm{n}=13$ ).

\section{Discussion}

The white badge of eagle owls has the same extension on the throat of males and females, but its reflectance properties were shown to be sex and season dependent, being higher in females and during the pre-laying period. The difference in the results obtained from the peripheric and central areas of the feather may be due to a stronger effect of abrasion on the former. Thus, lower reflectance values during the breeding months may be due to: (1) higher frequencies in this period of those behaviours that can potentially wear down the feather badge (e.g., incubation, chick protection and feeding), or (2) a longer period from the last moult. Eagle owl moult patterns are poorly known, apparently showing an irregular pattern. Thus, body feathers do not moult each year (Cramp 1985, Martínez et al. 2002). In any case, whatever the proximate explanation of this result, it is important to highlight that the period in which the badge reflectance was higher (September-February) corresponds to the time when territorial and courtship displays are at their peak (Penteriani 2002). Such temporal coincidence would support the hypothesis of a possible function of this trait in territorial and sexual behaviour.

On the other hand, eagle owls showed female-biased dichromatism in the brightness of their badges. The eagle owl is a resident, territorial and apparently plumagemonomorphic species characterized by strong mate bonds and female contribution to territorial defence (Penteriani 1996, 2002). Such characteristics may suggest that higher reflectance in females could be due to intersexual selection (male mate choice). In fact, in some monogamous species with biparental care, males seem to discriminate their mate in the same way that females do, the fitness of the former also being affected by female quality (e.g. Jones and Hunter 1993, 1999, Roulin 1999, Roulin et al. 2000; but see Smiseth and Amundsen 2000).

As additional or alternative explanation to intersexual competition, sexual dichromatism in eagle owls could have also emerged from female-female competition for both a mate and a territory. In general, female-female competition has received less attention than competition among males. However, the former can attain high levels of competition when females need an exclusive ownership of a territory and a mate (Arcese 1989, Ligon 1999). Moreover, female aggression represents the main explanation for the evolution of female plumage coloration in some avian groups (Irwin 1994). Empirical evidence supports the validity of these considerations in the case of eagle owls: also if in a weaker manner than males, females defend their territory too, against both intruding males and females, performing aggressive displays (Penteriani 1996, 2002, Penteriani and Delgado unpubl. data).

In either intra or intersexual selection contexts, the evolution of any signal would depend on its reliability at transmitting the quality of the owner (Maynard Smith 1982). In eagle owls, due to the subtle size sexual dimorphism, colour variability in the white badge could be used as a signal of female quality related to body size. In fact, in spite of the low sample size of our dataset, significant correlations were detected between female forearm and brightness. The result is even more relevant when we consider that the typical low density of eagle owl populations (Cramp 1985) may prevent birds from evaluating a high number of potential mates. The eagle owl, as many other raptor species, shows a reversed size dimorphism, females being bigger than males (in agreement with differences in white badge reflectance). Several hypotheses suggest that the larger size of females could have evolved from intrasexual competition for males (review in Massemin et al. 2000). In this way, the variability in the female white badge could have arisen as a mean to evaluate rivals (see "status-signalling hypothesis"' in Rohwer 1975). On the other hand, since female body size has been related to fertility in different raptor species (i.e., larger females produce more and larger eggs; Massemin et al. 2000), males could also benefit from choosing mates based on this trait. Along the same line, recent researches on another owl species, the barn owl Tyto alba, showed how plumage coloration (number of black spots) was positively correlated to female quality in terms of immuno-competence (Roulin et al. 2001a,b). The same authors suggest that the trait would be under intersexual selection (male mate choice) because: (a) males mated to highly spotted females obtain more immune-competent offspring (Roulin et al. 2000), (b) males consistently choose to mate with such females in different breeding seasons, and (c) their male offspring also preferred highly spotted females as mates (Roulin 1999).

The eagle owl is one of the most diurnal European owls, showing diurnal and crepuscular (i.e., dawn and dusk) patterns of activity (Cramp 1985, Penteriani 2000). Any visual signal used during this period should maximize the scarce light available. In the eagle owl, variability in the total amount of light reflected by the white throat could be exploited as high-contrast signal in dark backgrounds (e.g. vegetation, crepuscular sky) both in daylight and at twilight and night. Empirical evidence has already demonstrated that: (a) birds use very specific light environments for their displays where the plumage characteristics are maximized because of the ambient 
light and background properties (e.g., Endler 1993, Endler and Théry 1996), and (b) light environment plays a role in the evolution of colour patterns and signals (Endler and Théry 1996, McNaught and Owens 2002, Gomez and Théry 2004). Finally, the fact that the white badge can be concealed or showed facultatively with each calling bout suggests that it could have evolved as a "coverable badge", signalling threat or territory ownership when is required (see "coverable badge hypothesis", in Hansen and Rohwer 1986).

Future studies will need to experimentally investigate: (1) the role of this trait in both intrasexual competition and mate choice, (2) the possibility that the trait may reveal individual quality to conspecifics (e.g. body condition, immune-competence), and (3) the role of such an ornament in the context of multiple ornaments (i.e., call + white badge; e.g. Møller and Petrie 2002). In this species, vocal communication has been considered the way in which to convey information to conspecifics (Penteriani 2003). Our results suggest that this may be complemented by a subtle colour signal previously overlooked.

Acknowledgements - We thank J. Barreiro of the National Museum of Natural Sciences in Madrid and P. Cabot of the Estación Biológica de Doñ ana in Seville for their precious help in the collection of the eagle owl specimens. We thank also P. Ninni and C. Biard for their help and advice in the spectrometric study. J. Ewen, C. Maggio, J.J. Negro, R. Sandberg, G. Sorci, A. Velando and two anonymous referees made useful commentaries on the first draft of the manuscript.

\section{References}

Amundsen, T. 2000. Why are female birds ornamented? - Trends Ecol. Evol. 15: 149-155.

Andersson, M. 1994. Sexual selection. - Princeton University Press, Princeton.

Arcese, P. 1989. Intrasexual competition and the mating system in primarily monogamous birds: the case of the song sparrow. - Anim. Behav. 38: 96-111.

Berglund, A., Bisazza, A. and Pilastro, A. 1996. Armaments and ornaments: an evolutionary explanation of traits of dual utility. - Biol. J. Linn. Soc. 58: 385-399.

Bowmaker, J. K. and Martin, G. R. 1978. Visual pigments and colour vision in a nocturnal bird, Strix aluco (tawny owl). - Vision Res. 18: 1125-1130.

Cramp, S. 1985. Birds of the Western Palaearctic. Vol. IV. Terns to woodpeckers. - Oxford University Press, Oxford.

Crawley, M. J. 1993. GLIM for ecologists. - Blackwell Science, Oxford.

Cuthill, I. C., Partridge, J. C., Bennet, A. T. D., Church, S. C., Hart, N. S. and Hunt, S. 2000. Ultraviolet vision in birds. - Adv. Study Behav. 29: 159-214.

Darwin, C. 1871 . The descent of man and selection in relation to sex. - Murray, London.

Daunt, F., Monaghan, P., Wanless, S. and Harris, M. P. 2003. Sexual ornament size and breeding performance in female and male European shags Phalacrocorax aristotelis. - Ibis 145: 54-60.

Delgado, M. M. and Penteriani, V. 2004. Gender determination of Eurasian eagle owls (Bubo bubo) by morphology. - J. Raptor Res. 38: 375-377.
Eaton, M. D. and Lanyon, S. M. 2003. The ubiquity of avian ultraviolet plumage reflectance. - Proc. R. Soc. B 270: $1721-1726$.

Endler, J. A. 1990. On the measurements and classification of color in studies of animal color patterns. - Biol. J. Linn. Soc. 41: 315-352.

Endler, J. A. 1993. The color of light in forests and its implications. - Ecol. Monogr. 63: 1-27.

Endler, J. A. and Théry, M. 1996. Interacting effects of lek placement, display behaviour, ambient light and color patterns in three neotropical forest-dwelling birds. - Am. Nat. 148: 421-452.

Gomez, D. and Théry, M. 2004. Influence of ambient light on the evolution of colour signals: comparative analysis of a Neotropical rainforest bird community. - Ecol. Lett. 7: 279-284.

Griffiths, S. C., Owens, I. P. F. and Burke, T. 1999. Female choice and annual reproductive success favour less-ornamented male house sparrows. - Proc. R. Soc. B 266: 765770 .

Hansen, A. J. and Rohwer, S. 1986. Coverable badges and resource defence in birds. - Anim. Behav. 34: 69-76.

Irwin, R. 1994. The evolution of plumage dichromatism in the new world blackbirds: social selection on female brightness. - Am. Nat. 144: 890-907.

Jones, I. L. and Hunter, F. M. 1993. Mutual sexual selection in a monogamous seabird. - Nature 362: 238-239.

Jones, I. L. and Hunter, F. M. 1999. Experimental evidence for mutual inter- and intrasexual selection favouring a crested auklet ornament. - Anim. Behav. 57: 521-528.

Lessels, C. M. and Boag, P. T. 1987. Unrepeatable repeatabilities: a common mistake. - Auk 104: 116-121.

Ligon, J. D. 1999. The evolution of avian breeding systems. - Oxford University Press, Oxford.

Mahler, B. and Kempenaers, B. 2002. Objective assessment of sexual plumage dichromatism in the Picui dove. - Condor 104: $248-254$.

Martínez, J. A., Zuberogoitia, I. and Alonso, R. 2002. Rapaces nocturnas. Guía para la determinació n de la edad y el sexo en las Estrigiformes ibéricas. - Monticola Ediciones, Madrid.

Massemin, S., Korpimäki, E. and Wiehn, J. 2000. Reversed sexual size dimorphism in raptors: evaluation of the hypotheses in kestrels breeding in a temporally changing environment. - Oecologia 124: 26-32.

Maynard Smith, J. 1982. Evolution and theory of games. - Cambridge University Press, Cambridge.

McNaught, M. K. and Owens, I. P. F. 2002. Interspecific variation in plumage color among birds: species recognition or light environment? - J. Evol. Biol. 15: 505-514.

Mennill, D. J., Doucet, S. M., Montgomerie, R. and Ratcliffe, L. M. 2003. Achromatic color variation in black-capped chickadees, Poecile atricapilla : black and white signals of sex and rank. - Behav. Ecol. Sociobiol. 53: 350-357.

Møller, A. P. 1987. Variation in badge size in male house sparrows Passer domesticus: evidence for status signalling. - Anim. Behav. 35: 1637-1644.

Møller, A. P. and Petrie, M. 2002. Condition dependence, multiple sexual signals, and immunocompetence in peacocks. - Behav. Ecol. 13: 248-253.

Örnborg, R. F., Andersson, M., Griffith, S. C. and Sheldon, B. C. 2002. Seasonal changes in a ultraviolet structural colour signal in blue tits, Parus caeruleus. - Biol. J. Linn. Soc. 76: 237-245.

Owens, I. P. F. and Hartley, I. R. 1998. Sexual dimorphism in birds: why are there so many different forms of dimorphism? - Proc. R. Soc. B 265: 397-407.

Pärt, T. and Qvanströ m, A. 1997. Badge size in collared flight catchers predicts outcome of male competition over territories. - Behav. 54: 893-899.

Penteriani, V. 1996. The eagle owl. - Calderini Edagricole, Bologna. 
Penteriani, V. 2000. Diurnal vocal activity of young eagle owls and its implications in detecting occupied nests. - J. Raptor Res. 34: 232-235.

Penteriani, V. 2002. Variation in the function of eagle owl vocal behaviour: territorial defence and intra-pair communication? - Ethol. Ecol. Evol. 14: 275-281.

Penteriani, V. 2003. Breeding density affects the honesty of bird vocal displays as possible indicators of male/territory quality. - Ibis 145 (on-line): E127-E135.

Rohwer, S. 1975. The social significance of avian winter plumage variability. - Evolution 29: 593-610.

Roulin, A. 1999. Nonrandom pairing by male barn owls (Tyto alba ) with respect to a female plumage trait. - Behav. Ecol. 10: 688-695.

Roulin, A., Jungi, T. W., Pfister, H. and Dijkstra, C. 2000. Female barn owls (Tyto alba) advertise good genes. - Proc. R. Soc. B 267: 937-941.

Roulin, A., Dijkstra, C., Riols, C. and Ducrest, A.-L. 2001a. Female- and male-specific signals of quality in the barn owl. - J. Evol. Biol. 14: 255-266.

Roulin, A., Riols, C., Dijkstra, C. and Ducrest, A.-L. 2001b. Female plumage spottiness signals parasite resistance in the barn owl (Tyto alba ). - Behav. Ecol. 12: 103-110.
Ruiz-Martínez, I., Hodar, J. A. and Camacho, I. 1996. Territoriality and vocal behaviour of the European eagle owl Bubo bubo in the Sierra Morena mountains, southern Spain. - Alauda 64: 345-353.

Sæther, S. A., Fiske, P., Kålå s, J. A. and Gjul, J. M. 2000. Females of the lekking great snipe do not prefer males with whiter tails. - Anim. Behav. 59: 273-280.

SAS Institute. 2001. SAS/STAT software: changes and enhancements, version 8.2. - SAS Publishing, North Carolina, USA.

Smiseth, P. T. and Amundsen, T. 2000. Does female plumage coloration signal parental quality? A male removal experiment with the bluethroat (Luscinia s. svecica). - Behav. Ecol. Sociobiol. 47: 205-212.

Thusius, K. J., Peterson, K. A., Dunn, P. O. and Whittingham, L. A. 2001. Male mask size is correlated with mating success in the common yellowthroat. - Anim. Behav. 62: 435-446.

(Received 1 November 2004, revised 22 December 2004, accepted 20 January 2005.) 